\title{
What Factors Determine the Patients' Choice in Finding Their Office Urologist?
}

\author{
Athanasios Zachariou (D) ${ }^{1,2}$ \\ Fotios Dimitriadis (D) $^{3}$ \\ Vaios Papadimitriou ${ }^{4}$ \\ Petros Tsafrakidis ${ }^{5}$ \\ Stefan $\mathrm{M} \mathrm{Haensel}^{6}$ \\ Charalampos Mamoulakis $\left.{ }^{7}\right)^{7}$ \\ Helmut Haas $\mathbb{D}^{8}$ \\ 'Department of Urology, University of \\ loannina, loannina, Greece; '² Department \\ of Urology, Physical Medicine and \\ Rehabilitation Centre Eu Prattein, Volos, \\ Greece; ${ }^{3}$ Department of Urology, \\ Aristotle University of Thessaloniki, \\ Thessaloniki, Greece; ${ }^{4}$ Department of \\ Urology, Private Practice, Lamia, Greece; \\ ${ }^{5}$ Department of Urology, Mediterranean \\ Hospital of Cyprus, Limassol, Cyprus; \\ ${ }^{6}$ Department of Urology, Franciscus \\ Hospital, Rotterdam, The Netherlands; \\ ${ }^{7}$ Department of Urology, Medical School, \\ University of Crete, Heraklion, Greece; \\ ${ }^{8}$ EAU Section of Outpatient and Office \\ Urology, Heppenheim, Germany
}

Purpose: The present study aimed to investigate how patients identify a quality urologist in primary health care and how they determine and evaluate their provider's qualities before their first examination.

Patients and Methods: A specific questionnaire (The ESUO Questionnaire) was prepared to describe the domains that influence the patient's evaluation and summarize the urologist related characteristics and behaviours that the patients estimate are more important. A total of 335 patients, over 18 years of age, presented in primary healthcare urology practice, completed the survey. The participants were divided into three age groups; 18-39 years of age (111 patients), 40-59 years of age (111 patients) and 113 patients 60 years of age and older.

Results: The majority of patients $(68.4 \%)$ selected that the urologist must be efficient and well trained. This attitude was primarily expressed in patients $\geq 60$ years of age. Individuals under 60 years old stated that they expect a detailed examination and that the patient should be the urologist's priority. The majority of the patients evaluates friends or family's proposals concerning the urologist's quality primarily and believes that there is at least good quality of urological health care.

Conclusion: Most patients evaluate primarily the effectiveness of the care they receive instead of the urologist's personality traits or personal relationships.

Keywords: urologist, primary health care, ESUO questionnaire, health care quality

\section{Introduction}

The model of a patient-friendly healthcare system is currently a subject of a European discussion, with numerous implications for urology practice. Healthcare policy effects are manifested through clinical practice guidelines, payment reform, and the overall structure of the healthcare system. ${ }^{1}$

Furthermore, the traditional paternalistic approach between the doctor and the patient has transformed into a more patient-centred attitude. Modern healthcare systems accept that patients are clients or, instead, consumers of healthcare services. ${ }^{2}$ Healthcare professionals usually encourage their patients to get actively involved in their medical evaluation and treatment to ensure that they satisfactorily fulfill their specific needs and provide quality care. Medical knowledge has become a shared resource between the doctors and the patient, and the ultimate goal is personalized medicine: treatment is customized to the individual patient. ${ }^{3}$

A content patient could affect and sometimes alter another customer's choice of care provider, resulting in substantial financial profits. ${ }^{4,5}$ A satisfied patient usually establishes a long-term relationship with a specific healthcare professional, provides greater loyalty and has an increased tendency to recommend that doctor to others. ${ }^{6,7}$
Correspondence: Athanasios Zachariou Tel +302421026937

$\mathrm{Fax}+302421026932$

Email zahariou@otenet.gr 
Given its many benefits, it is not surprising that there is considerable interest in investigating contributing factors to patient satisfaction with the doctor and the topics that influence patients' decisions. Patients' selection of the individual doctor has shown a strong association with the greater fulfilment of expectations regarding the medical experience and treatment outcome. ${ }^{8-10}$

Although there are many papers concerning patient satisfaction after their evaluation from the healthcare professional, there is little knowledge regarding patients' criteria to choose their urologist. ${ }^{11-16}$ Furthermore, urologists usually cope with conditions that some people consider embarrassing, like sexual dysfunction, sexually transmitted diseases or incontinence. In Europe, most urologists are males, and a significant part of their workforce is employed outside the hospital, like outpatient and office urologists.

The present study aimed to investigate how patients identify a quality urologist in primary health care and how they determine and evaluate their provider's qualities before their first examination. Identifying how patients make their selection will ultimately help urologists understand what their potential patients interpret as significant issues to their health care. Our results might help explore the patient's healthcare preferences, differences between doctors in primary health care and diminish barriers to seeking optimal urology healthcare.

\section{Materials and Methods}

The study was conducted in Greece from June 2020 to August 2020 at three outpatient primary urology healthcare settings. The European Association of Urology Section of Outpatient and Office Urology (ESUO) questionnaire was created, especially for this trial. Its primary purpose was to describe all the separate known patients' measures. The ESUO section aims to address core issues that affect and are of interest to educated urologists who treat outpatients predominantly in their professional profile.

A detailed questionnaire concerning the urologist's patient-related determinants should focus on personality features, sociocultural beliefs, and previous experiences with urologists. A clinical judgment discrimination process was of utmost help to consider all possible items and identify the pertinent questions relevant to patient determinants. The initial version was evaluated, and questions deemed non-relevant or duplicated were rejected in the final version. Pilot testing of the final version of the ESUO questionnaire was conducted on 20 individuals in the waiting room for the first appointment with a specific urologist. This pilot revealed no issues with understanding the questions, and the majority of patients found it easy to proceed while waiting for their urologic evaluation. The research staff weighed and included most of these patients' comments to compose the final version of the ESUO Questionnaire. This consisted of a short introduction with socio-demographic characteristics and 14 questions (Supplementary File 1).

The trial included patients over 18 years of age, waiting for the first urological appointment with a specific urologist in an office setting and willing to complete the questionnaire.

All the participants received an oral and written explanation about the study objectives, and office nurses collected the patients' completed questionnaires. All participants gave written informed consent before completing the questionnaire. Patients unwilling to participate in the survey or to provide informed consent were excluded. The procedure of this study complied with the guidelines provided by the Declaration of Helsinki, and the the research ethics committee of Physical Medicine and Rehabilitation Centre EU PRATTEIN approved the study before its onset.

The patients divided into three groups; Group I with patients 18-39 years of age, Group II with patients 40-59 years of age and Group III with patients $\geq 60$ years to compare the answers between the three age groups.

The sample size was calculated using the number of urologists working in the region, the number of outpatient visits in the district hospital and private healthcare settings, the primary healthcare urology cost and the total regional population. The prevalence of an outpatient urologic evaluation in the region was assumed up to $4 \%$. This yielded 220 patients, but it was added $10 \%$ for incomplete contribution and $20 \%$ for non-responders. Thus, the final minimal sample size was more than 305 participants; we finally collected 335 questionnaires.

The primary outcome measures were to describe the criteria that influence the patient's choice of a specific urologist and summarize the patient's estimated physicianrelated characteristics and behaviours. Secondary outcomes were to compare the patients' choices between the different age groups. Statistically significant differences in the ranking of the three age categories' answers were examined using the Kruskal Wallis test. Non-parametric multiple comparisons followed to clarify pairwise differences between the possible age pairs. Statistical significance was set at 0.05 ( $\mathrm{p}$ value $<0.05$ ) for all comparisons, 
and the analysis was conducted using the statistical software SPSS v 23.0.

\section{Results}

In total, 533 new patients presented to the surveyed urology practices over the time course of our study. The survey yielded 362 responders (68\% participation rate), and a total of 335 completed questionnaires were eligible for evaluation and included in the study (62.8\% total response rate). There were 111 patients in the age group 18-39 (33.1\%), 111 in the age group 40-59 (33.1\%) and 113 patients $\geq 60(33.8 \%)$.

In our study, most patients (94\%) have state health care coverage, and only a few $(6 \%)$ have chosen not to have public insurance or were unable to do so. Nearly $18 \%$ of the patients in private healthcare urology settings had a personal or company insurance program that allowed them to visit a urologist in the private sector.

Concerning the patient's perceptions of the urologist's professional knowledge and expertise, the most important topic was the precise diagnosis, proper treatment (49.6\%), and the second was the detailed examination (33.7\%). Treatment outcome was considered more important than their physician's training qualities or their participation in scientific congresses.

Availability, accessibility and financial topics are always crucial in selecting a physician. Questions focused on the patient's perception of the time spent in healthcare settings and whether the doctor was available when needed. It disclosed that an excellent office environment and polite staff are the most important (49.9\%), especially to older patients.

When the patients decide which element is the most critical, most $(68.4 \%)$ select that the urologist must be efficient and well trained; the physician's positive personal attitude, essential according to patient satisfaction measures, displays the subsequent preference before the initial evaluation (Table 1).

One out of three patients was 60 years of age or older. The majority of urological problems like benign prostatic hyperplasia and incontinence were healthcare issues of older patients.

Surprisingly, $33 \%$ of patients were younger than 40 years of age. These patients visited the outpatient clinic because of urinary tract infections (eg prostatitis, cystitis, pyelonephritis, sexually transmitted diseases, 57\%). Other healthcare issues included infertility problems (11\%) and skin conditions involving the penis and the genitals (10\%). Communication, relational contact and the physician's attitudes were critical aspects in patient's satisfaction measures. Physicians' exhibited care about their health issues was this patient group's main expectation (43.9\%).

The ESUO Questionnaire included topics with negative questions; the reason was to ensure that patients responded to the survey honestly. As a result, in the negative question concerning the essential characteristic of a lousy quality urologist, most of the patients $(65.7 \%)$ answered that it is the physician's low efficiency.

Our study group valued their friends or family's perspective primarily and, secondly, their general practitioner's opinion to select the urologist. It is exciting to see that patients do not trust the private insurance company's sites, professional sites or website groups. As a result, they feel very confident when another doctor recommends their urologist $(43.9 \%)$ or a friend or a family member (49\%).

When it comes to the connection between cost and quality, our study population's perception was that highquality healthcare services usually have a higher price (47.5\%). However, one out of three patients believes that

Table I The Most Critical Aspect of the Quality Urologist Before Patient's Consultation

\begin{tabular}{|l|c|c|c|c|c|c|}
\hline \multicolumn{2}{|l|}{} & Ist Choice & 2nd Choice & 3rd Choice & 4th Choice & 5th Choice \\
\hline Positive personality traits & No pts & 57 & 149 & 82 & 47 & 0 \\
Efficient and well trained & $\%$ & $17,0 \%$ & $44,5 \%$ & $24,5 \%$ & $14,0 \%$ & $0,0 \%$ \\
& No pts & 229 & 58 & 37 & 11 & 0 \\
Accessible and affordable & $\%$ & $68,4 \%$ & $17,3 \%$ & $11,0 \%$ & $3,3 \%$ & $0,0 \%$ \\
& No pts & 24 & 89 & 99 & 123 & 0 \\
Excellent office environment and & $\%$ & $7,2 \%$ & $26,6 \%$ & $29,6 \%$ & $36,7 \%$ & $0,0 \%$ \\
polite staff & No pts & 25 & 38 & 114 & 154 & 4 \\
\hline
\end{tabular}

Abbreviation: No pts, number of patients. 
there is no relationship between the quality and cost of health care. Most patients think that there is at least a good quality of urological health care $(96 \%)$. The statistically significant differences between the different age groups in the various topics are described in Table 2.

In the question "How do you evaluate the information you get from any of the following sources concerning the quality of your urologists?" there were some striking statistically significant differences in the answers of the three age groups (Table 3).

\section{Discussion}

Although there is a lot of concern about health care quality, very few papers describe the selection criteria patients use to find their preferred physician. The expected satisfaction from the doctor is more pressing for urology healthcare issues. Urology consultations usually include a detailed history, an extensive pelvic examination, and in many cases, an ultrasound evaluation. Patients frequently report to urologists delicate topics such as sexually transmitted diseases, infertility problems, sexual dysfunctions and incontinence issues. Therefore, it is expected that for these topics, the patient prefers to ask a urologist directly in primary healthcare practice without the necessity of seeing a primary-care physician and a long waiting time for a referral. ${ }^{17}$

According to research from the Associated PressNORC Center for Public Affairs Research, Americans tend to focus on specific aspects of quality relating to doctor-patient interactions and doctor personality traits rather than the effectiveness of the care provided or the patient's health outcomes. ${ }^{18}$ According to Berger et al, essential factors when selecting a urologist, may be the hospital's reputation, in addition to scheduling convenience. $^{13}$ In our study, patients believe that a urologist's individual quality is the successful care outcome. The provided treatment's efficiency is an expected and reasonable important factor since urologic symptoms like incontinence and voiding disorders have a significant psychosocial burden and limit social consequences. An incomplete therapeutic effect in a topic like incontinence or sexual dysfunction may cause substantial lifestyle changes in individuals. ${ }^{19,20}$

Analyzing the preferences of the three different age groups, it is exciting that patients $\geq 60$ years prefer an experienced urologist compared to other age groups. Someone could claim that this agrees with Berger et al, who mentioned the hospital's reputation as a vital factor and Tamalunas et al, who described the importance of professional skills and academic criteria. ${ }^{13,16}$ Board certifications and academic degrees provide acceptable rational proof of an efficient and well-trained urologist. On the other hand, younger individuals believe that the more important of an experienced urologist is a detailed examination and think that the patient should be the urologist's priority.

Table 2 Statistical Significant Differences in the Answers of Three Patients' Age Groups

\begin{tabular}{|c|c|c|c|c|c|}
\hline & & \multicolumn{3}{|c|}{ Age Group } & \multirow[t]{2}{*}{ p-value } \\
\hline & & 18-39 Yrs & 40-59 Yrs & $\geq 60$ Yrs & \\
\hline $\begin{array}{l}\text { Cares about patients, the patient is } \\
\text { his/her priority }\end{array}$ & Mean $\pm S D$ & $1.82 \pm 0.84$ & $1.70 \pm 0.92$ & $2.01 \pm 0.95$ & $\begin{array}{c}0.02 \\
40-59 v s \geq 60\end{array}$ \\
\hline $\begin{array}{l}\text { Pays attention to details and spends } \\
\text { time examining patients }\end{array}$ & Mean $\pm S D$ & $\mathrm{I} .8 \mathrm{I} \pm 0.87$ & $2.0 I \pm 0.97$ & $2.18 \pm 0.89$ & $\begin{array}{c}0.003 \\
18-39 v s \geq 60\end{array}$ \\
\hline Experienced urologist & Mean $\pm S D$ & $2.82 \pm 0.88$ & $2.89 \pm 0.82$ & $2.43 \pm 1.01$ & $\begin{array}{c}0.00 \mid \\
\mid 8-39 v s \geq 60 \\
40-59 v s \geq 60\end{array}$ \\
\hline $\begin{array}{l}\text { There is an excellent office } \\
\text { environment, and polite staff }\end{array}$ & Mean $\pm S D$ & $1.72 \pm 0.96$ & $1.86 \pm 1.16$ & $2.12 \pm 1.11$ & $\begin{array}{c}0.015 \\
18-39 v s \geq 60\end{array}$ \\
\hline $\begin{array}{l}\text { Accept my insurance, he/she is } \\
\text { affordable }\end{array}$ & Mean \pm SD & $3.6 I \pm 0.96$ & $3.63 \pm 0.99$ & $3.30 \pm 1.08$ & $\begin{array}{c}0.017 \\
18-39 v s \geq 60 \\
0.012 \\
40-59 v s \geq 60\end{array}$ \\
\hline
\end{tabular}

Abbreviation: SD, standard deviation. 
Table 3 Statistically Significant Differences Between the Three Age Groups in the Question "How Do You Evaluate the Information You Get from Any of the Following Sources Concerning the Quality of Your Urologists?"

\begin{tabular}{|c|c|c|c|c|c|}
\hline & & \multicolumn{3}{|c|}{ Age Group } & \multirow[t]{2}{*}{ p-value } \\
\hline & & 18-39 Yrs & 40-59 Yrs & $\geq 60$ Yrs & \\
\hline Local newspaper or magazine & Mean \pm SD & $4.14 \pm 1,28$ & $4.03 \pm 1.17$ & $3.68 \pm 1.01$ & $\begin{array}{c}0.02 \mid \\
\mid 8-39 v s \geq 60\end{array}$ \\
\hline Other doctors & Mean \pm SD & $2.39 \pm 1.36$ & $1.76 \pm 0.96$ & $1.85 \pm 0.92$ & $\begin{array}{c}0.00 \mid \\
\mid 8-39 v s \geq 60 \\
18-39 v s 40-59\end{array}$ \\
\hline Health insurance company & Mean $\pm S D$ & $4.53 \pm 1.13$ & $4.72 \pm 1.29$ & $4.25 \pm 1.11$ & $\begin{array}{c}0.003 \\
40-59 v s \geq 60\end{array}$ \\
\hline Professional websites & Mean \pm SD & $3.53 \pm 1.25$ & $3.83 \pm 1.09$ & $4.42 \pm 1.03$ & $\begin{array}{c}0.001 \\
18-39 v s \geq 60\end{array}$ \\
\hline $\begin{array}{l}\text { Online on a community group's } \\
\text { website }\end{array}$ & Mean \pm SD & $4.69 \pm 1.53$ & $4.89 \pm 1.20$ & $5.35 \pm 1.10$ & $\begin{array}{c}0.00 \mid \\
\mid 8-39 v s \geq 60 \\
40-59 v s \geq 60\end{array}$ \\
\hline
\end{tabular}

Abbreviation: SD, standard deviation.

Someone would expect that most patients in a private healthcare setting would be $\geq 60$ years of age. According to our results, one out of three patients is younger than 40 years of age. The main urologic problems of our young patients were urinary tract infections and especially prostatitis. Prostatitis is a common urinary tract disease that accounts for $25 \%$ of all office visits globally to urological primary healthcare practices. ${ }^{21}$ It seems that younger people prefer to consult in private healthcare settings and evaluate the polite staff and the excellent office environment compared to older patients. On the other hand, individuals $\geq 60$ years of age have financial topics as a priority. They prefer the free public sector or an outpatient setting that accepts their insurance compared to other age groups. This is in agreement with the findings of the National Center for Health Statistics, where Medicare was the primary expected source of payment for the majority of visits to office-based physicians by adults aged 65 and over. ${ }^{22}$

General opinions about the quality of health care one receives are related to how easy it is to find trustworthy quality information. Interestingly, like Americans, our study population does not access valuable information about their urologists from sources that can provide official data on health care delivery and outcomes. ${ }^{18}$ As a result, family, friends or the general practitioner serve as familiar sources of such information. Remarkably, in the internet era, the critical element to attract new patients is to become visible in the community by demonstrating excellent outcomes and providing outstanding service. In our study, website groups were put in the last position regarding their credibility about a future consultation from a urologist. According to data from a tertiary hospital in Germany, the personal recommendation by a physician or a relative friend is of high significance, too. ${ }^{16}$ In the same study, the age group 20-40 is more enthusiastic about searching for a urologist using the Internet. ${ }^{16}$ On the other hand, a significant proportion of patients search the internet regarding their medical condition before presenting to the clinic. ${ }^{13}$

Analyzing the preferences of the three different age groups, it is fascinating that patients $\geq 60$ years follow their insurance company proposals, probably due to financial reasons. The younger age group relies upon professional websites to evaluate their urologist and do not follow their general practitioner's suggestions.

Someone could claim that the preferences of Greek patients are not translatable to the rest of Europe because of cultural differences. Studies advocate more similarities than differences among Southern Europe (SE) countries that support the hypothesis for considering them as the southern band of European Union countries. ${ }^{23}$ In Southern European countries, the family has a substantial impact on individual choices, and it is reasonable to suppose an explanation about the strong household influences on health perception. ${ }^{24,25}$ 
One of the study limitations is that the ESUO Questionnaire is patient self-reported research. After carefully evaluating similar study topics, the research team formed the questions but did not formally validate the ESUO Questionnaire. According to our knowledge, there is no validated questionnaire concerning the patient's criteria to select their physician. The study focused on officebased urologists and evaluated individuals from multiple outpatient settings in a selected region to overcome limitations. In the study period (June to August 2020), there were limited measures about Covid-19 in the study region (masks and social distancing). Eventually, there was the minimal impact of the pandemic on the patients' attitudes. Furthermore, the presented participation rate $(62 \%)$ follows similar studies in other healthcare field reports, displaying a $58-63 \%$ varying percentage. ${ }^{26,27}$ The present study did not evaluate different urological conditions, diseases severity and the necessity of operation.

It seems somewhat obvious that patients prioritize proper treatment. We believe that an optimal treatment outcome and the patient's involvement in disease management are essential in the era of personalized medicine. To ensure a successful treatment outcome, patients usually choose experienced professionals. On the other hand, if urologists want to assure that their patients receive the proper treatment, they mainly have to provide efficient treatment customized to the individual.

The EAU Section of ESUO has already organized a parallel study in central European countries. The primary outcome will compare the patients' preferences in different European regions and the secondary outcome will produce more actionable items for urologists. Obviously, future studies in all urology healthcare markets are needed, including patient satisfaction with their choice of the physician after treatment.

\section{Conclusions}

This multicentred questionnaire study suggests that most new patients in primary healthcare urology practice focus on the care's effectiveness rather than the doctor-patient interactions and urologist's personality traits. Patients report that they select their urologist evaluating word-of-mouth and personal recommendations from friends, relatives and referring doctors rather than internet-based information. Finally, individuals believe that higher quality health care generally comes at a higher cost.

\section{Data Sharing Statement}

The data of the current study are available from the corresponding author on reasonable request.

\section{Author Contributions}

All authors made a significant contribution to the work reported, whether that is in the conception, study design, execution, acquisition of data, analysis and interpretation, or in all these areas; took part in drafting, revising or critically reviewing the article; gave final approval of the version to be published; have agreed on the journal to which the article has been submitted; and agree to be accountable for all aspects of the work.

\section{Funding}

No funding was received for conducting this study.

\section{Disclosure}

The authors have no conflicts of interest to declare that are relevant to the content of this article.

\section{References}

1. Pitts D, Sammon JD. Healthcare policy and urologic practice. Curr Opin Urol. 2017;27:348-353. doi:10.1097/MOU.0000000000000410

2. Kupfer JM, Bond EM. Patient satisfaction and patient-centered care: necessary but not equal. JAMA. 2012;308:139-140. doi:10.1001/ jama.2012.7381

3. Greenhalgh T, Hinton L, Finlay T, et al. Frameworks for supporting patient and public involvement in research: systematic review and co-design pilot. Health Expect. 2019;22:785-801. doi:10.1111/ hex. 12888

4. Lucas JS. The satisfaction survey that matters. Am J Obstet Gynecol. 2012;206:518-522. doi:10.1016/j.ajog.2012.01.043

5. Preble S, Wachs WW. The new face of growth. Healthc Fin Manage. 2014;68:70-75.

6. Sirdifield C, Godoy Caballero A, Windle K, et al. Comparing importance and performance from a patient perspective in English general practice: a cross-sectional survey. Fam Pract. 2016;33:179-185. doi:10.1093/fampra/cmw004

7. Gérard L, François M, de Chefdebien M, Saint-Lary O, Jami A. The patient, the doctor, and the patient's loyalty: a qualitative study in French general practice. $B r J$ Gen Pract. 2016;66:e810-e818. doi:10.3399/bjgp16X687541

8. Marcinowicz L, Pawlikowska T, Konstantynowicz J, Chlabicz S. New insight into the role of patients during medical appointments: a synthesis of three qualitative studies. Patient. 2014;7:313-318. doi:10.1007/s40271-014-0056-1

9. Merel SE, McKinney CM, Ufkes P, Kwan AC, White AA. Sitting at patients' bedsides may improve patients' perceptions of physician communication skills. J Hosp Med. 2016;11:865-868. doi:10.1002/ jhm.2634

10. Mercado F, Mercado M, Myers N, Hewit M, Haller NA. Patient preferences in choosing a primary care physician. J Prim Care Community Health. 2012;3:125-131. doi:10.1177/2150131 911421802 
11. Amir H, Beri A, Yechiely R, Amir Levy Y, Shimonov M, Groutz A. Do urology male patients prefer same-gender urologist? Am J Mens Health. 2018;12:1379-1383. doi:10.1177/1557988316650886

12. Kim SO, Kang TW, Kwon D. Gender preferences for urologists: women prefer female urologists. Urol J. 2017;14:3018-3022.

13. Berger GK, Medairos R, Regala $P$, et al. Factors influencing patient selection of urologists. Urology. 2020;137:19-25. doi:10.1016/j. urology.2019.08.066

14. Wynn J, Johns Putra L. Patient preference for urologist gender Int J Urol. 2020. doi:10.1111/iju. 14418

15. Donahue R, Russell D, de Riese C, Smith C, de Riese W, Medway A. Patients willing to wait: arrival time, wait time and patient satisfaction in an ambulatory urology clinic. Urol Pract. 2017;4:1-6. doi:10.1016/j.urpr.2016.02.003

16. Tamalunas A, Buchner A, Hennenberg $M$, et al. Choosing a specialist: an explanatory study of factors influencing patients in choosing a urologist. Urol Int. 2021;105:749-756. doi:10.1159/ 000517291

17. Kursch ED, Ulchaker JC. Office Urology. The Clinician's Guide. Totowa, NJ: Humana Press; 2001.

18. The Associated Press-NORC Center for Public Affairs Research. Finding quality doctors: how Americans evaluate provider quality in the United States, research highlights; [cited July 2014]. Available from: www.apnorc.org. Accessed December 6, 2021.

19. Aoki Y, Brown HW, Brubaker L, Cornu JN, Daly JO, Cartwright R. Urinary incontinence in women. Nat Rev Dis Primers. 2017;3:17042. doi:10.1038/nrdp.2017.42
20. Allen M, Walter E. Health-related lifestyle factors and sexual dysfunction: a meta-analysis of population-based research. $J$ Sex Med. 2018;15:458-475. doi:10.1016/j.jsxm.2018.02.008

21. Ullah Khan F, Ullah Ihsan A, Ullah Khan H, et al. Comprehensive overview of prostatitis. Biomed Pharmacother. 2017;94:1064-1076. doi:10.1016/j.biopha.2017.08.016

22. Ashman JJ, Rui P, Okeyode T. Characteristics of office-based physician visits, 2015. NCHS data brief, no 310. Hyattsville, MD: National Center for Health Statistics; 2018.

23. Nikandrou I, Apospori E, Papalexandris N. Cultural and leadership similarities and variations in the southern part of the European Union. $J$ Leadersh Organ Stud. 2003;9(3):61-84. doi:10.1177/107179 190300900307

24. Gabriele D, Jordi G. Similarity of perceived health between household members: the "Mutual Influences" Hypothesis, Patrizia Giannantoni and Viviana Egidi. In: A Demographic Perspective on Gender, Family and Health in Europe. Springer Nature; 2018:133-154.

25. Ferrer RL, Palmer R, Burge S. The family contribution to health status: a population-level estimate. Ann Fam Med. 2005;3 (2):102-108. doi:10.1370/afm.266

26. Yahanda AT, Lafaro KJ, Spolverato G, Parwik TM. A systematic review of the factors that patients use to choose their surgeon. World J Surg. 2016;40:45-55. doi:10.1007/s00268-015-3246-7

27. Manning BT, Bohl DD, Wang KC, Hamid KS, Holmes GP, Lee S. Factors influencing patient selection of a foot and ankle surgeon. Foot Ankle Spec. 2018;11:315-321. doi:10.1177/1938 640017729499
Patient Preference and Adherence

\section{Publish your work in this journal}

Patient Preference and Adherence is an international, peer-reviewed, open access journal that focusing on the growing importance of patient preference and adherence throughout the therapeutic continuum. Patient satisfaction, acceptability, quality of life, compliance, persistence and their role in developing new therapeutic modalities and compounds to optimize clinical outcomes for existing disease

\section{Dovepress}

states are major areas of interest for the journal. This journal has been accepted for indexing on PubMed Central. The manuscript management system is completely online and includes a very quick and fair peer-review system, which is all easy to use. Visit http:// www.dovepress.com/testimonials.php to read real quotes from published authors. 